\title{
Optimisation of the Postharvest Treatment with Thymol to Control Mango Anthracnose
}

\author{
Marc Chillet1,2*, Jérome Minier1,2, Mathilde Hoarau1,2, Jean-Christophe Meile1,2 \\ ${ }^{1}$ CIRAD UMR QUALISUD, 7 Chemin de l'IRAT, Ligne Paradis, Saint Pierre, Ile de La Réunion, France \\ ${ }^{2}$ QUALISUD, Université de Montpellier, CIRAD, Université de la Réunion, Montpellier SupAgro, Université d'Avignon et des \\ Pays de Vaucluse, Montpellier, France \\ Email: ^marc.chillet@cirad.fr
}

How to cite this paper: Chillet, M., Minier, J., Hoarau, M. and Meile, J.-C. (2020) Optimisation of the Postharvest Treatment with Thymol to Control Mango Anthracnose. American Journal of Plant Sciences, 11, 1235-1246.

https://doi.org/10.4236/ajps.2020.118087

Received: June 11, 2020

Accepted: August 14, 2020

Published: August 17, 2020

Copyright $\odot 2020$ by author(s) and Scientific Research Publishing Inc. This work is licensed under the Creative Commons Attribution International License (CC BY 4.0).

http://creativecommons.org/licenses/by/4.0/

\begin{abstract}
Anthracnose, caused by the fungus called Colletotrichum gloeosporioides, is the main postharvest disease that affects mango production on Reunion Island. Fruits for the export market are always treated with chemicals. The use of chemical treatment is not in adequation with consumer expectations, and the increasing emergence of fungicide-resistant isolates promotes the development of alternatives methods. The principal objective of this work was to use antimicrobial properties of thymol as an alternative postharvest treatment on mango. Thymol diluated in a penetrating agent solution was effective on mango anthracnose. At a concentration of $0.025 \%$, Thymol limited necrosis development due to pathogens during fruit storage. This treatment can stimulate some of polyphenols biosynthesis involved in the fruit resistance to postharvest disease, particularly the synthesis of gallic acid and resorcinol. With this final concentration of $0.025 \%$ thymol, the treatment did not affect fruit maturation and quality, especially the peel colour and sugar content. Importantly, the treatment did not show any detectable effect on organoleptic qualities of the fruit.
\end{abstract}

\section{Keywords}

Mango, Mangifera indica, Anthracnose, Colletotrichum gloeosporioides, Biological Control, Phenolic Compound, Thymol

\section{Introduction}

Mango (Mangifera indica L.) is one of the most widely grown tropical fruits in the world because of its high economic potential [1]. Postharvest diseases are responsible for important losses especially for fruit destinated to exportation market. Anthracnose is caused by Colletotrichum gloeosporioides and repre- 
sents the main post-harvest disease affecting mango in all zones of mango production. This disease impacts fruit quality, directly affecting fruit shelf life and commercial value. The pathogens contaminate fruits in the field during fruit growth; conidia of Colletotrichum are vehiculated by rain water and can germinate on the fruit peel surface in order to form appressoria, which are the quiescent structures of the fungus. Lesions appear during ripening or after wounding. Disease control is generally done by postharvest application of chemicals [2]. However, the increasing emergence of fungicide-resistant isolates and problems related to fungicide toxicity [3], new alternatives strategies for controlling this disease have been proposed, including the use of essential oils properties [4].

There is a lot of essential oils (EOs) possessing antimicrobial activity against fruit pathogens [5]. The thyme (Thymus vulgaris L. thymoliferum) produces several active compounds like thymol. This compound was shown to be very effective to control diseases of sweet cherry [6] and table grape [7] and to limit decay caused by fungal pathogens in cherry tomato [8], in avocado [9] [10], in banana [11] and in papaya [12].

Thymol showed high in vitro efficacy against both spore germination and mycelial growth of $C$. gloeosporioides [13]. Recent works on avocado and mango also demonstrated the effectiveness of thyme oil and thymol for controlling postharvest diseases, by the stimulation of biochemical pathways involved in natural defence [14] [15].

The biochemical resistance of mango is principally based on Gallic acid and resorcinol production. Gallic acid has the capacity to form molecular structures such as gallotannins [16], and some resorcinols such as

5-(12-heptadecenyl)-resorcinol has a high fungi toxic activity [17]. Flavonoids in the fruit peel are also implicated in host resistance [18]. Thus, the chemical properties and antimicrobial activity of thymol can elicit physiological responses of the fruit to control C. gloeosporioides. However, high doses of thymol may inhibit certain metabolic pathways involved in fruit resistance; the synthesis of resorcinol decreased in fruits treated with doses of thymol higher than $0.1 \%$ [15]. Similarly, thymol has a negative effect on fruit ripening, and can totally block the ripening process [15]. The optimal concentration of thymol in a treatment solution is investigated.

The main objective of our study was evaluating an alternative postharvest treatment method against anthracnose disease in mango with several concentrations of thymol. The effect of several dipping thymol solution on anthracnose development was evaluated. The effect of these treatments on fruit physiology and sensorial quality was tested too.

\section{Materials and Methods}

\subsection{Plant Material}

The mango (Mangifera indica) var. José was cultivated by a producer of Saint Gilles les Hauts, in Saint Paul, Reunion Island $\left(21^{\circ} 6^{\prime} \mathrm{S} 55^{\circ} 32^{\prime} \mathrm{E}\right.$-tropical cli- 
mate-average annual temperature $=25^{\circ} \mathrm{C}$, rainfall $=1500 \mathrm{~mm} /$ year-ferrallitic soils). Fruits were harvested at a commercial maturity stage for exportation.

\subsection{Pathogen}

The MUCL 43868 strain of Colletotrichum gloeosporioides (Penzig) was used for all experiments. The strain was cultivated on potato dextrose agar (PDA) medium at $27.5^{\circ} \mathrm{C}$ in the dark. This strain, from the pathogen collection of the Catholic University of Leuven (Leuven, Belgium), was isolated from Mexican mangoes by GL Hennebert [19].

\subsection{Thymol Solution}

Treatment solutions were prepared with crystals of pure thymol (number CAS 89-83-8) from Xeda International SA (Saint Andiol, France) diluted in terpene preparations made with the commercial product Heliosol ${ }^{\circledR}$ (665 g/L terpenic alcohol) prepared at $2 \mathrm{~mL} / \mathrm{L}$, referred to as $\mathrm{H}$ in this paper.

\subsection{In Vivo Tests-Fruit Inoculation}

MUCL 43868 was cultivated in Petri dishes for 21 days on PDA. Health fruits were selected, and the peel area to be inoculated was washed with $70 \%$ ethanol. Fruit inoculation was performed according to [10] by uniformly wounding (a cross: $2 \mathrm{~mm}$ deep and $10 \mathrm{~mm}$ wide) a flat zone of the fruit with a sterilized cork-borer and inoculating it with $20 \mu \mathrm{L}$ of a spore suspension of MUCL43868 at $10^{5}$ spores $/ \mathrm{mL}$. To ensure that anthracnose development was due to our inoculated strain, the peels from inoculated fruits were placed on Saboureau media amended with chloramphenicol and left for 10 days at $27^{\circ} \mathrm{C}$. The identification of the re-isolated fungi was based on morphological criteria. After inoculation, fruits were maintained at room temperature for $24 \mathrm{~h}\left(21^{\circ} \mathrm{C}, 85 \%\right.$ relative humidity).

Inoculated fruits were then dipped during 2 minutes in 1) water as a control $(\mathrm{C}), 2)$ the terpene solvent $(\mathrm{H})$ as a second control, and 3) thymol/terpene solvent (several concentrations of thymol) and stocked to air to dry at room temperature.

The effect of different concentrations (\%) of thymol in the solvent $(0.1 \%$ of thymol: T0.1\%; $0.075 \%$ of thymol: T0.075\%; $0.05 \%$ of thymol: T0.05\%; $0.025 \%$ of thymol: T0.025\%; $0.01 \%$ of thymol: T0.01\%) was compared with (H) and (C) controls.

The experiment was repeated in triplicate (70 fruits for each replicate of the experiment-10 fruits per modality (T0.5\%; T0.1\%; T0.05; T0.025\%; T0.01\%; C and $\mathrm{H})$. The objective was to determine the most effective concentration on disease development that did not affect fruit quality.

Inoculated and treated fruits were packed in sealed plastic boxes (30 L) and maintained at $20^{\circ} \mathrm{C}$ for 7 days. Observations of wound anthracnose were recorded at the end of the storage time (7 days). The length (L) and width (w) of 
the developed necrosis was measured on the inoculation area of each fruit and the surface of each necrosis was calculated by the formula of the area of an ellipse: L X w X $\pi / 4$.

\subsection{Biochemical Analyses}

Fruits were analysed at the end of the storage. All fruits were weighed before and after storage to measure weight loss with a precision balance Sartorius CP3202S (Sartorius Lab Instruments GmbH \& Co. Goettingen, Germany. Peel and pulp were separated and frozen at $-80^{\circ} \mathrm{C}$. Biochemical analyses were performed on total soluble solids (TSS measured by an electronic refractometer Pocket Refractometer Atago on fruit pulp) and on colour with a chroma meter (Minolta CR 300). The colour was measured in the Lab system and was represented by chroma $\left(C=\left(a^{2}+b^{2}\right)^{1 / 2}\right)$. Polyphenols and resorcinol-like compounds were analysed using high-performance liquid chromatography (HPLC) on fruit peels. HPLC analysis was performed using a Dionex Ultimate 300 apparatus (Dionex Co., Sunnyvale, CA, USA) equipped with a diode array detector. The column used was a reverse-phase Waters Symmetry Shield C18, 250 X $4.6 \mathrm{~mm}, 5 \mu \mathrm{m}$.

\subsection{Sensorial Analysis}

We performed a triangular test (NF ISO 4120) with 24 judges and two types of sample; a sample with mangoes treated with $0.025 \%$ solution thymol, and a control sample with mangoes treated with water.

\subsection{Statistical Analysis}

A randomized block design approach was adopted in this study. The experiments were repeated in triplicate, and the data were analysed with the general linear model (GLM) procedure in the Excel Stat computer programme. Mean values were separated by LSD values (5\%) using the least significant difference (LSD) test and homogenous groups were determined using the Newman-Keuls test.

\section{Results}

\subsection{Effect of Thymol on Wound Anthracnose Development}

The effect of thymol on wound anthracnose development was significant (Figure 1 and Figure 2). After 7 days of storage, there was no development of necrosis on the fruits inoculated and treated with $0.075 \%$ and $0.1 \%$ thymol $(0$ $\mathrm{mm}^{2}$ ), and a very light development on fruits treated with $0.05 \%$ thymol (58 $\left.\mathrm{mm}^{2}\right)$. Fruits treated with $0.025 \%$ thymol $\left(118 \mathrm{~mm}^{2}\right)$ also presented significantly reduced necrosis surfaces when compared to controls (no significative difference between T0.1\%, T0.075\%, T0.05\% and T0.025\%). Fruits treated with $0.01 \%$ thymol showed necrosis surfaces of approximately $320 \mathrm{~mm}^{2}$ on average. Control fruits $(\mathrm{C}$ and $\mathrm{H})$ presented large necrosis totally different to thymol treated fruits $\left(842 \mathrm{~mm}^{2}\right.$ for $\mathrm{H}$ and $626 \mathrm{~mm}^{2}$ for $\mathrm{C}$ ). 
Effect of thymol on weight loss during storage (Table 1).

The percentage of weight loss was the lowest for fruits treated with water (C) or the terpene solvent $(\mathrm{H})$ (approximately $4.7 \%$ and $6.6 \%$ ). This was significantly different from weight loss observed in fruits treated with the highest concentration of thymol (T0.1\% presented about $9 \%$ of weight loss).

\subsection{Effect of Thymol on Peel and Biochemical Quality Parameters}

Two quality parameters related to fruit ripening were measured. Fruit peel colour and total soluble sugar (TSS) are presented in Table 1.

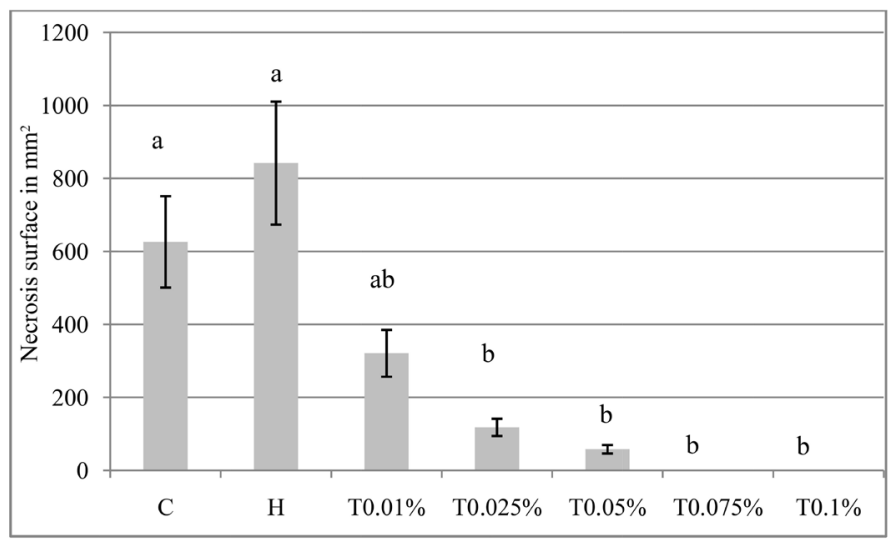

Figure 1. Necrosis surface 7 days after inoculation of fruit with a solution of C. gloeosporioides spores for mangoes from the different treatments. T0.1\% $=0.1 \%$ thymol treatment; $\mathrm{T} 0.075 \%=0.075 \%$ thymol treatment; $\mathrm{T} 0.05 \%=0.05 \%$ thymol treatment; $\mathrm{T} 0.025 \%=$ $0.025 \%$ thymol treatment, $\mathrm{T} 0.01 \%=0.01 \%$ thymol treatment $\mathrm{C}=$ water treatment; $\mathrm{H}=$ terpene treatment. The letters $\mathrm{a}$ and $\mathrm{b}$ represent the homogeneous groups determined by the Newman-Keuls test at a threshold of $5 \%$.

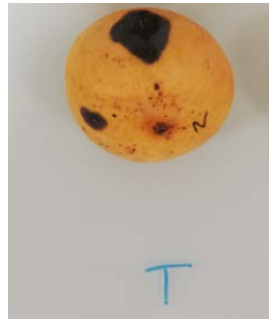

(a)

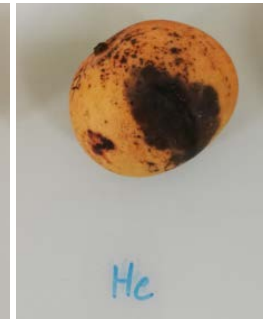

(b)

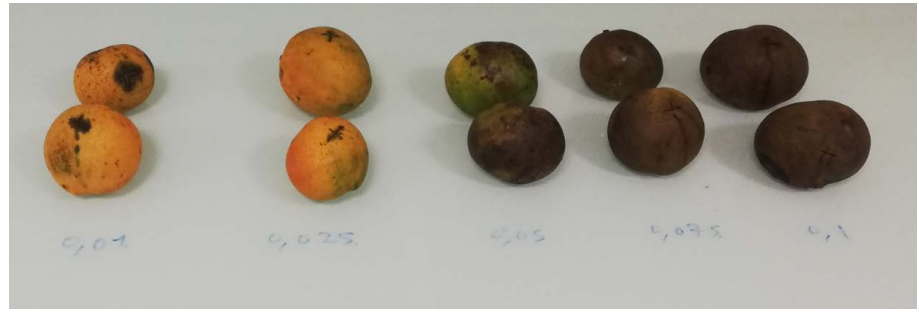

(c)

Figure 2. (a) Photo of a mango from treatment C, (b) Photo of a mango from treatment H, (c) Photos of mangoes from treatment T.01\% thymol (left), T0.025\% thymol, T0.05\% thymol, T0.075\% thymol and T0.1\% thymol (right). 
Table 1. Weight loss (\%), colour peel (C) and Brix $\left({ }^{\circ}\right)$ of fruits treated with T0.1\% $=0.1 \%$ thymol treatment; $\mathrm{T} 0.075 \%=0.075 \%$ thymol treatment; $\mathrm{T} 0.05 \%=0.05 \%$ thymol treatment; $\mathrm{T} 0.025 \%=0.025 \%$ thymol treatment, $\mathrm{T} 0.01 \%=0.01 \%$ thymol treatment $\mathrm{C}=$ water treatment; $\mathrm{H}=$ terpene treatment. The letters $\mathrm{a}, \mathrm{b}, \mathrm{c}$ and $\mathrm{d}$ represent the homogeneous groups determined by the Newman-Keuls test at a threshold of $5 \%$.

\begin{tabular}{|c|c|c|c|}
\hline & Weight loss (\%) & Colour Peel (C) & TSS ${ }^{\circ}$ Brix \\
\hline $\mathrm{C}$ & $4.77 \pm 0.51(b)$ & $48.28 \pm 2.62(\mathrm{a})$ & $21.07 \pm 1.13(\mathrm{a})$ \\
\hline $\mathrm{H}$ & $6.65 \pm 0.96(\mathrm{ab})$ & $49.83 \pm 5.20(\mathrm{a})$ & $20.43 \pm 1.07$ (a) \\
\hline Т0.01\% & $6.82 \pm 0.75(\mathrm{ab})$ & $52.43 \pm 3.03(\mathrm{a})$ & $20.45 \pm 1.27$ (a) \\
\hline Т0.025\% & $8.04 \pm 1.74(\mathrm{ab})$ & $50.76 \pm 3.04(\mathrm{a})$ & $19.83 \pm 2.11(\mathrm{a})$ \\
\hline T0.05\% & $8.38 \pm 2.42(\mathrm{a})$ & $36.42 \pm 9.42(b)$ & $20.61 \pm 1.80(\mathrm{a})$ \\
\hline Т0.075\% & $7.40 \pm 2.19(\mathrm{ab})$ & $24.26 \pm 7.58(\mathrm{c})$ & $16.82 \pm 1.97(b)$ \\
\hline Т0.1\% & $9.02 \pm 2.67(\mathrm{a})$ & $17.29 \pm 2.97(\mathrm{~d})$ & $14.16 \pm 1.52(\mathrm{c})$ \\
\hline
\end{tabular}

Fruit maturation in the highest thymol concentration treatment was impeded. The parameters that characterized the peel colour were also very different between $\mathrm{T} 0.1 \%$, $0.075 \%$ and $\mathrm{T} 0.05 \%$ treatments and the $\mathrm{C}$ and $\mathrm{H}$ controls, and lowest thymol concentration treatment (Table 1).

As expected, the peel colour values of treated fruits with more than $0.05 \%$ thymol were significantly different from the controls $(\mathrm{C}$ and $\mathrm{H})$ and low thymol concentration (T0.01\%, T0.025\%). The $\mathrm{T} 0.01 \%$ and $\mathrm{T} 0.025 \%$ values were not significantly different from the $\mathrm{H}$ and $\mathrm{C}$ values and the ripening profiles of $\mathrm{T} 0.01 \%, \mathrm{~T} 0.025 \%, \mathrm{H}$ and $\mathrm{C}$ fruits were equivalent. This is consisitant with a visual observation of the fruits as shown in Figure 2. The highest thymol concentration led to a brown colored peel.

The fruit sugar soluble content of C, H, T0.01\%, T0.025\% and T0.05\% fruits were indistinguishable after 7 days of storage but were significantly different from $\mathrm{T} 0.0 .075 \%$ and $\mathrm{T} 0.1 \%$ fruits. $\mathrm{C}, \mathrm{H}, \mathrm{T} 0.01 \%, \mathrm{~T} 0.025 \%$ and $\mathrm{T} 0.05 \%$ fruits evolved during the storage period, and the soluble sugars were synthesized normally, which was not the case for T0.1\% and T0.075\% fruits in which the maturation of the pulp was impeded. The ripening process was affected by thymol treatments, and the lack of starch degradation was used as an indicator of blocked maturation.

\subsection{Effect of Thymol on Polyphenolic Compound Biosynthesis}

Figure 3 shows the gallic acid contents after the application of the different treatments. For $\mathrm{C}$ and $\mathrm{H}$ fruits, the values were equivalent and without significant differences at 5\% (about $6000 \mu \mathrm{g} / \mathrm{g} \mathrm{DM}$ ). On the other hand, T0.01\% and T0.025\% fruits showed much higher values $(11720 \mu \mathrm{g} / \mathrm{g}$ DM and $9837 \mu \mathrm{g} / \mathrm{g} \mathrm{DM})$ compared to other treatments. Gallic acid synthesis was therefore stimulated by $0.01 \%$ and $0.025 \%$ thymol treatments. However, the T0.075\% and T0.1\% fruits 
exhibited the lowest values ( $4320 \mu \mathrm{g} / \mathrm{g} \mathrm{DM}$ and $1361 \mu \mathrm{g} / \mathrm{g} \mathrm{DM})$, even lower than the $\mathrm{H}$ control. Therefore, the high concentration of thymol seemed to inhibit gallic acid synthesis in mango.

Figure 4 shows the levels of resorcinol in mango peel after different thymol treatments. It was found that until $0.025 \%$ of thymol, an increase in thymol concentration was correlated with an increase of the resorcinol content in the fruits. T0.025\% fruits presented the highest level of resorcinol content $(65 \mu \mathrm{g} / \mathrm{g}$ $\mathrm{DM})$ and was significally different from the other treatments.

There was no significant difference between $\mathrm{C}, \mathrm{H}, \mathrm{T} 0.075 \%$ and $\mathrm{T} 0.05 \%$, but fruits from T0.1\% treatments showed significantly lower levels of resorcinol (0 $\mu \mathrm{g} / \mathrm{g} \mathrm{DM})$. These observations suggest an inhibition of resorcinol synthesis in mango peel following a treatment using a high concentration of thymol.

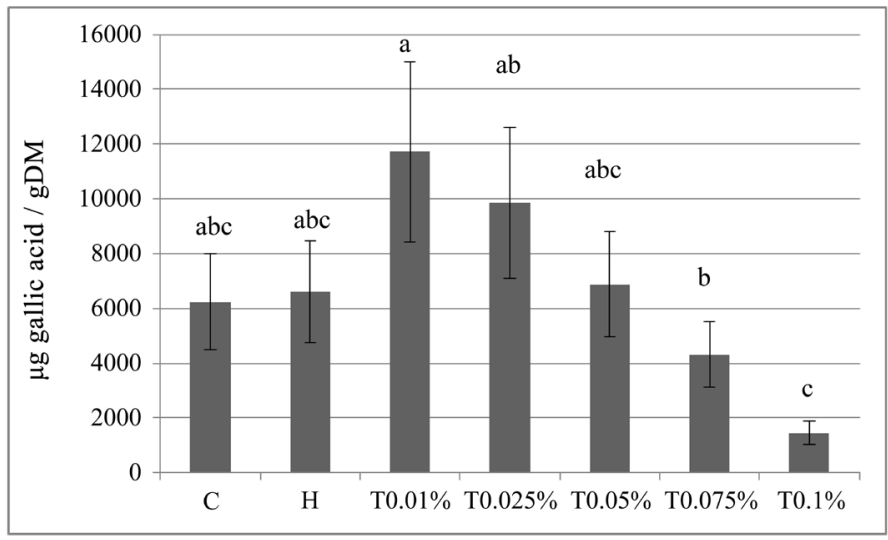

Figure 3. Gallic acid content in the peel of fruits subjected to different treatments. T0.1\% $=0.1 \%$ thymol treatment; $\mathrm{T} 0.075 \%=0.075 \%$ thymol treatment; $\mathrm{T} 0.05 \%=0.05 \%$ thymol treatment; $\mathrm{T} 0.025 \%=0.025 \%$ thymol treatment, $\mathrm{T} 0.01 \%=0.01 \%$ thymol treatment $\mathrm{C}=$ water treatment; $\mathrm{H}=$ terpene treatment. The letters $\mathrm{a}, \mathrm{b}$ and $\mathrm{c}$ represent the homogeneous groups determined by the Newman-Keuls test at a threshold of $5 \%$.

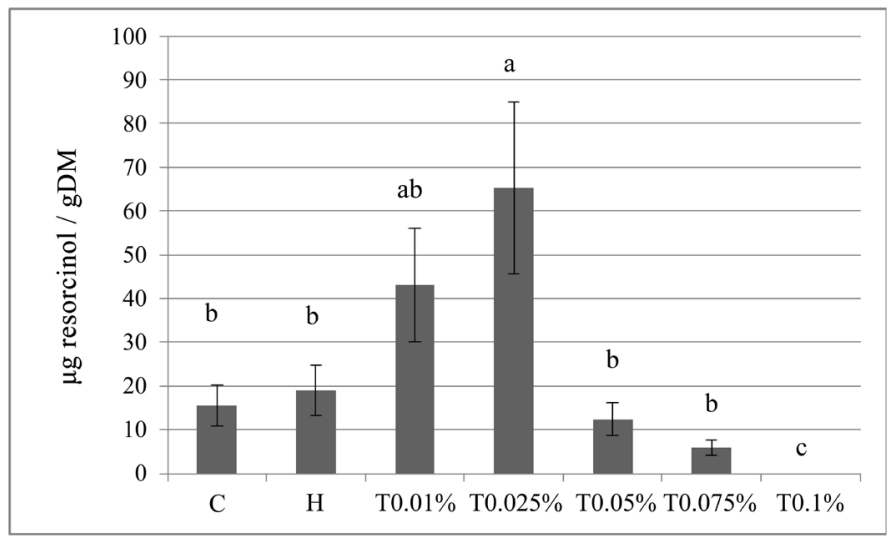

Figure 4. Resorcinol content in the peel of fruits subjected to different treatments. T0.1\% $=0.1 \%$ thymol treatment; $\mathrm{T} 0.075 \%=0.075 \%$ thymol treatment; $\mathrm{T} 0.05 \%=0.05 \%$ thymol treatment; $\mathrm{T} 0.025 \%=0.025 \%$ thymol treatment, $\mathrm{T} 0.01 \%=0.01 \%$ thymol treatment $\mathrm{C}=$ water treatment; $\mathrm{H}=$ terpene treatment. The letters $\mathrm{a}, \mathrm{b}$ and $\mathrm{c}$ represent the homogeneous groups determined by the Newman-Keuls test at a threshold of $5 \%$. 
Figure 5 and Figure 6 show the levels of the two mains flavonoids (quercetine and catechin) in mango peel after the different thymol treatments. For quercetin, no significant difference between all treatments (at 5\% level) was observed suggesting that thymol had no effect on peel quercetine levels. However, an important decrease of catechin level correlated with thymol concentration increase was observed. No more catechin was detected in fruit peel when fruit were treated with $0.1 \%$ thymol (Figure 5 ).

\subsection{Effect of Thymol on Sensory Analysis}

A triangular test with 24 judges and two types of sample was performed; a sample with mangoes treated with a $0.025 \%$ thymol solution, and a control sample with mangoes treated with water. At the end of the test, 12 (50\%) correct judgements were made, which is not significant at $\mathrm{P}<0.05$ [20]. The triangular test at

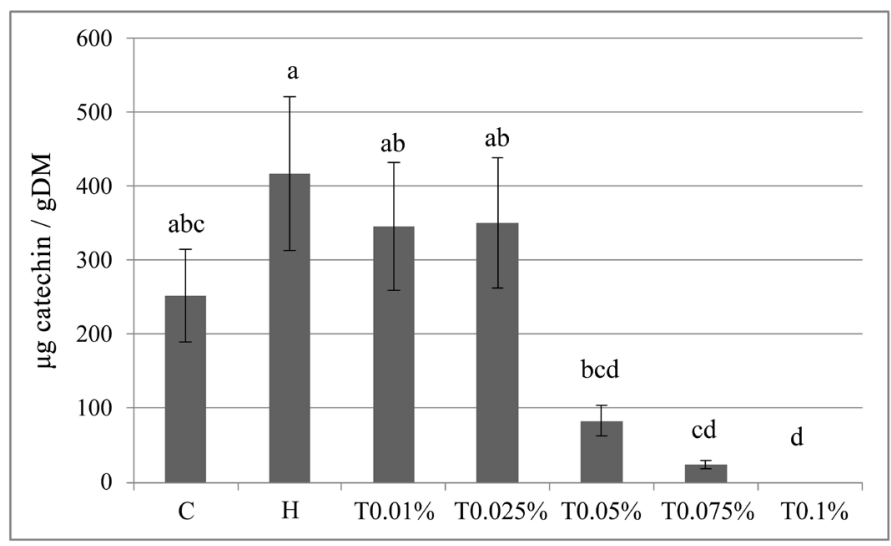

Figure 5. Catechin content in the peel of fruits subjected to different treatments. T0.1\%= $0.1 \%$ thymol treatment; $\mathrm{T} 0.075 \%=0.075 \%$ thymol treatment; $\mathrm{T} 0.05 \%=0.05 \%$ thymol treatment; $\mathrm{T} 0.025 \%=0.025 \%$ thymol treatment, $\mathrm{T} 0.01 \%=0.01 \%$ thymol treatment $\mathrm{C}=$ water treatment; $\mathrm{H}=$ terpene treatment. The letters $\mathrm{a}, \mathrm{b}, \mathrm{c}$ and $\mathrm{d}$ represent the homogeneous groups determined by the Newman-Keuls test at a threshold of 5\%.

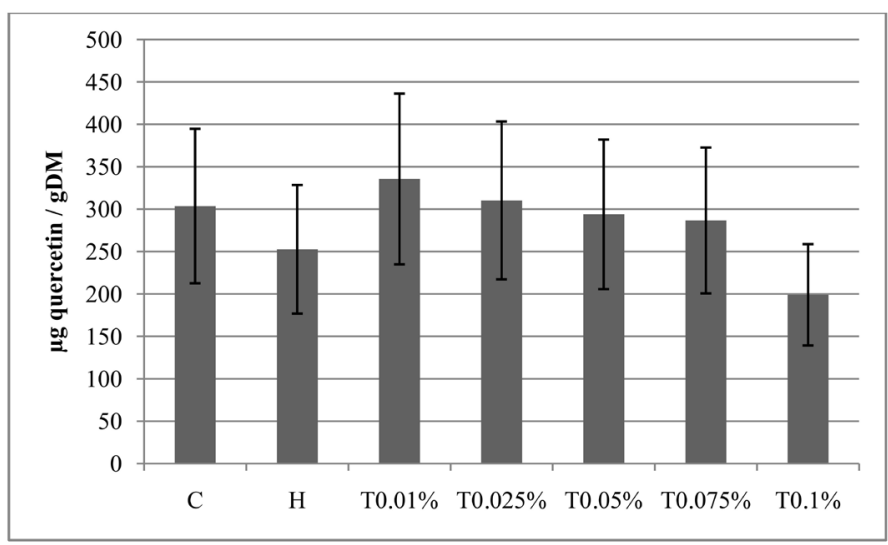

Figure 6. Quercetin content in the peel of fruits subjected to different treatments. T0.1\% $=0.1 \%$ thymol treatment; T0.075\% $=0.075 \%$ thymol treatment; T0.05\% $=0.05 \%$ thymol treatment; $\mathrm{T} 0.025 \%=0.025 \%$ thymol treatment, $\mathrm{T} 0.01 \%=0.01 \%$ thymol treatment $\mathrm{C}=$ water treatment; $\mathrm{H}=$ terpene treatment. 
the 5\% threshold showed no significant difference between the samples; the judges were therefore unable to statistically differentiate the fruits treated with thymol from the untreated fruits.

\section{Discussion}

The aim of the experiment was to determine the best concentrations of thymol to use for postharvest treatment with a measurable effect in vivo on the development of necrosis due to $C$. gloeosporioides on mango (cv José), given that thymol is highly fungi toxic to this pathogen in vitro [13] and in vivo [15] with no negative effect on fruit quality.

The first result obtained dealt with weight loss. Treatment with a $0.1 \%$ thymol solution led to important weight loss during the 7 days following the treatment. This weight loss may be the consequence of a stress phenomenon resulting from the use of high thymol concentration. The brown peel colour of the treated fruits supports this interpretation: the excess of thymol caused a stress similar to a salt stress, leading to an increase in respiration and reactive oxygen species (ROS) synthesis, resulting in an overall browning of the peel [21].

Nevertheless, despite the visual appearance of the peel of the $\mathrm{T} 0.1 \%$ and $\mathrm{T} 0.075 \%$ fruits, thymol (diluted in $\mathrm{H}$ ) had a very strong fungitoxic effect, whether it was on the development of wound anthracnose. This result is in accord with first result with higher concentration of thymol [15].

$\mathrm{H}$ is a penetrating agent. It allows thymol molecules to penetrate into the fruit and to prevent the development of the pathogen that has a subcuticular hypha at the time the treatment is applied, making superficial treatments ineffective [22]. $\mathrm{H}$ alone had no effect on the disease, confirming that thymol penetrates into the skin and then blocks the pathogen. Seven days after treatment with a $0.1 \%$ thymol solution, the thymol content was approximately $140 \mathrm{ng} / \mathrm{g}$ FM in the fruit peel (data not showed).

The second aim of the experiment was to choose the optimal thymol concentration in the $\mathrm{H}$ penetrating agent to obtain a treatment solution that would make it possible to control anthracnose without impacting fruit maturation and quality.

The T0.1\% and T0.075\% treatments were totally effective and prevented the development of the pathogen after inoculation of a calibrated solution of spores on the wound (wound anthracnose). However, the $0.05 \%$ and $0.025 \%$ thymol solution appeared effective on fruits as necrosis developed in comparison to $\mathrm{H}$ and $\mathrm{C}$ control fruits.

Fruit maturation patterns were evaluated in terms of colour and sugar content. Our results showed that $\mathrm{T} 0.01 \%, \mathrm{~T} 0.025 \%$ treated fruits evolved similar to $\mathrm{C}$ and $\mathrm{H}$ control fruits, whereas the maturation of the $\mathrm{T} 0.1 \%, \mathrm{~T} 0.05 \%$ and T0.075\% fruits was affected by the treatment. This is in accordance with our previous studies on mango for the highest concentration of thymol [15].

Phenolic compounds are mainly involved in the mechanisms of fruit peel re- 
sistance. Our data shed new light on the effect of thymol on fruit biochemistry. For gallic acid, there is an increase in level for $0.01 \%$ and $0.025 \%$ thymol concentrations, and a decrease with higher thymol concentrations. Low thymol content stimulates gallic acid synthesis and high thymol contents inhibited the production of gallic acid. For resorcinol content, the same type of results was observed: high thymol contents inhibited the production of resorcinol, and low thymol content stimulates resorcinol synthesis, especially T0.025\%. For the two flavonoids measured, no stimulation of biosynthesis was observed; catechin content decrease with the increase of thymol, and quercetin content is not affected by the post harvest treatment.

Our observations are in agreement with the observations of other studies on comparable host-pathogen interactions [9] [10] [23]. A post harvest treatment with $0.01 \%$ or $0.025 \%$ of thymol can stimulate a part of the biochemical mechanism of fruit resistance against Colletotrichum gloeosporioides.

Our results showed that the treatment with $0.025 \%$ thymol permitted an effective control of anthracnose development with no effect on fruit maturity (color and sugar content). This is why sensory analyses were performed with fruits treated with this thymol concentration. Interestingly, the triangular test showed that this treatment did not affect the fruit taste, which makes it a very promising treatment for mango anthracnose.

\section{Conclusion}

This study showed that the use of thymol in the postharvest treatment of mango to prevent anthracnose development is a valid option. Thymol, associated with a penetrating agent such as Heliosol ${ }^{\circ}$, had a strong fungi toxic activity in vivo and stimulated some defence pathways of the fruit. The concentrations to be applied must be well calibrated to prevent fruit maturation. A treatment with a solution of thymol calibrated at $0.025 \%$ permitted a good control of the disease with no detectable effect on fruit quality. For a total control of anthracnose, additional studies must be carried out using the synergie of several essential oils including thymol and optimization should be considered according to mango variety.

\section{Acknowledgements}

This study was partly funded by the PO Cosaq project (Regional FEDER Reunion Island) and D2Biofruits project. We acknowledge Xeda International SA for the supply of thymol.

\section{Conflicts of Interest}

The authors declare no conflicts of interest regarding the publication of this paper.

\section{References}

[1] Evans, E.A. and Mendoza, O.J. (2009) World Mango Trade and the Economics of 
Mango Production. In: Litz, R.E., Ed., The Mango: Botany, Production and Uses, Chapter 16, CABI Publishing, Wallingford, 606-628. https://doi.org/10.1079/9781845934897.0606

[2] Johnson, G.I., Sharp, J.L., Milne, D.L. and Oosthuyse, S.A. (1997) Postharvest Technology and Quarantine Treatments. In: Litz, R.E., Ed., The Mango Botany, Production and Uses, CAB International, Wallingford, 447-507.

[3] Sanders, G.M., Korsten, L. and Wehner, F.C. (2000) Survey of Fungicide Sensitivity in Colletotrichum gloeosporioides from Different Avocado and Mango Production Areas in South Africa. European Journal of Plant Pathology, 106, 745-752. https://doi.org/10.1023/A:1026523021296

[4] Droby, S., Wisniewski, M., Macarisin, D. and Wilson, C. (2009) Twenty Years of Postharvest Biocontrol Research: Is It Time for a New Paradigm? Postharvest Biology and Technology, 52, 137-145. https://doi.org/10.1016/j.postharvbio.2008.11.009

[5] Regnier, T., Du Plooy, W., Combrinck, S. and Botha, B. (2008) Fungitoxicity of Lippia scaberrima Essential Oil and Selected Terpenoid Components on Two Mango Postharvest Spoilage Pathogens. Postharvest Biology and Technology, 48, 254-258. https://doi.org/10.1016/j.postharvbio.2007.10.011

[6] Serrano, M., Martínez-Romero, D., Castillo, S., Guillén, F. and Valero, D. (2005) The Use of Antifungal Compounds Improves the Beneficial Effect of MAP in Sweet Cherry Storage. Innovative Food Science and Emerging Technologies, 6, 115-123. https://doi.org/10.1016/j.ifset.2004.09.001

[7] Guillén, F., Zapata, P.J., Martínez-Romero, D., Castillo, S., Serrano, M. and Valero, D. (2007) Improvement of the Overall Quality of Table Grapes Stored under Modified Atmosphere Packaging in Combination with Natural Antimicrobial Compounds. Journal of Food Science, 72, 185-190.

https://doi.org/10.1111/j.1750-3841.2007.00305.x

[8] Feng, W., Chen, J., Zheng, X. and Liu, K. (2011) Thyme Oil to Control Alternaria alternata in Vitro and in Vivo as Fumigant and Contact Treatments. Food Control, 22, 78-81. https://doi.org/10.1016/j.foodcont.2010.05.010

[9] Bill, M., Sivakumar, D., Korsten, L. and Thompson, A.K. (2014) The Efficacity of Combined Application of Edible Coatings and Thyme Oil in Inducing Resistance Components in Avocado (Persea americana Mill) against Anthracnose during Post-Harvest Storage. Crop Protection, 64, 158-167.

https://doi.org/10.1016/j.cropro.2014.06.015

[10] Sellamuthu, P.S., Mafune, M., Sivakumar, D. and Soundy, P. (2013) Thyme Oil Vapour and Modified Atmosphere Packaging Reduce Anthracnose Incidence and Maintain Fruit Quality in Avocado. Journal of Science of Food and Agriculture, 93, 324-331. https://doi.org/10.1002/jsfa.6135

[11] Vilaplana, R., Pazmino, L. and Valencia-Chamorro, S. (2015) Control of Anthracnose, Caused by Colletotrichum musae on Postharvest Organic Banana by Thymol. Postharvest Biology and Technology, 138, 58-63. https://doi.org/10.1016/j.postharvbio.2017.12.008

[12] Sarkhosh, A., Schaffer, B., Vargas, A.I., Palmateer, A.J., Lopez, P., Soleymani, A. and Farzanet, M. (2018) Antifungal Activity of Five Plant-Extracted Essential Oils against Anthracnose in Papaya Fruit. Biological Agriculture and Horticulture, 34, 18-26. https://doi.org/10.1080/01448765.2017.1358667

[13] Chillet, M., Minier, J., Ducrocq, M. and Meile, J.C. (2018) Postharvest Treatment of Mango: Potential Use of Essential Oil with Thymol to Control Anthracnose Development. Fruits, 73, 153-157. https://doi.org/10.17660/th2018/73.3.2 
[14] Bill, M., Sivakumar, D., Beukes, M. and Kortsen, L. (2016) Expression of Pathogenesis-Related (PR) Genes in Avocados Fumigated with Thyme Oil Vapour and Control of Anthracnose. Food Chemistry, 194, 938-939.

https://doi.org/10.1016/j.foodchem.2015.08.105

[15] Chillet, M., Minier, J., Hoarau, M. and Meile, J.C. (2019) Potential Use of Thymol to Control Anthracnose Development in Mango. European Journal of Plant Pathology, 155, 943-952. https://doi.org/10.1007/s10658-019-01825-9

[16] Karunanayake, L.C., Adikaram, N., Kumarihamy, B.M.M., Bandara, B.M.R. and Abayasekara, C. (2011) Role of Antifungal Gallotannins, Resorcinols and Chitinases in the Constitutive Defense of Immature Mango (Mangifera indica L.) against Colletotrichum gloeosporioides. Journal of Phytopathology, 159, 657-664. https://doi.org/10.1111/j.1439-0434.2011.01818.x

[17] Cojocaru, M., Droby, S., Glotter, E., Goldman, A., Goetlib, H.E., Jacoby, B. and Prusky, D. (1986) 5-(12-heptadecenyl)-resorcinol, the Major Compound of the Antifungal Activity in the Peel of Mango Fruit. Phytochemistry, 25, 1093-1095. https://doi.org/10.1016/S0031-9422(00)81560-5

[18] Sivankalyani, V., Feygenberg, O., Diskin, S., Wright, B. and Alkan, N. (2016) Increased Anthocyanin and Flavonoids in Mango Fruit Peel Are Associated with Cold and Pathogen Resistance. Postharvest Biology and Technology, 111, 132-139. https://doi.org/10.1016/j.postharvbio.2015.08.001

[19] Prihastuti, H., Cai, L., Chen, H., McKenzie, E.H.C. and Hyde, K.D. (2009) Characterisation of Colletotrichum Species Associated with Coffee Berries in Northern Thailand. Fungal Diversity, 39, 89-109.

[20] Stone, H. and Sidel, J.L. (2004) Sensory Evaluation Practices. Academic Press Inc., Tragon Corporation, Redwood City, 408 p.

[21] Parent, C., Capelli, N. and Dat, J. (2008) Formes réactives de l'oxygène, stress et mort cellulaire chez les plantes. C. R. Biologies, 331, 255-261. https://doi.org/10.1016/j.crvi.2008.02.001

[22] Coates, L.M., Muirhead, I.F., Irwin, J.A.G. and Gowanlock, D.H. (1993) Initial Infection Processes by Colletotrichum gloeosporioides on Avocado Fruit. Mycological Research, 97, 1363-1370. https://doi.org/10.1016/S0953-7562(09)80171-8

[23] Obianom, C. and Sivakumar, D. (2017) Natural Plant Volatiles as an Alternative Approach to Control Stem-End Rot in Avocado Cultivars. Journal of Phytopathology, 166, 1-9. https://doi.org/10.1111/jph.12653 